\title{
El sueño de la razón produce monstruos (Sobre la novela de Leonardo Padura: El hombre que amaba a los perros)
}

\section{Gina Picart}

La entusiasta recepción de una novela centrada en el asesinato de Trotsky en México, y que utiliza como escenario las décadas de tiranía stalinista en la Unión Soviética y su influjo nefasto sobre el pueblo ruso, la Guerra Civil española y el comunismo mundial, prueba que, lejos de haber perdido actualidad, el tema sigue estando al rojo vivo en el candelero de la Historia, hecho incontestable que convierte automáticamente esta obra en un producto apetecible para el mercado del libro, pues la Revolución de Octubre conforma, junto con el nazismo, el dúo de eventos históricos más relevantes del siglo $\mathrm{XX}$, y uno de los de mayor peso y trascendencia en la historia de la humanidad. Con semejante apoyatura y amparado bajo el sello de Tusquets, irrumpe en el panorama editorial El hombre que amaba a los perros, el último título de Leonardo Padura.*

Tenemos, pues, un libro que reúne un gran tema y un gran género literario, la novela histórica, probablemente el más difícil de todos los géneros narrativos. A esta fórmula tan prometedora se suma la aureola que envuelve a Padura, excelente periodista y comunicador, célebre autor de novelas policiales y creador de Mario Conde, un icono detectivesco aceptado por el público, pero cuya acreditación definitiva sigue siendo cuestionada en algunos círculos literarios. Y acude a acrecentar la expectativa un detalle que siempre confiere un sabor muy picante a los asuntos de libros: el autor cree que se han publicado en Cuba más de 4000 ejemplares, pero solo se vendieron unos pocos centenares en la Feria del Libro de La Habana, y ni la entrega de tickets numerados logró garantizar que los asistentes a la presentación que tuvo lugar en las bóvedas de La Cabaña pudieran comprar en paz su codiciado libro. ¿Y el resto...? El resto es silencio, porque nadie volvió a ver al hombre que amaba a los perros paseando sus galgos rusos por los anaqueles de las librerías nacionales. Dicen que el libro se esfumó. En verdad esta novela no ha podido gozar de mejor parafernalia para colocarla en la mira de todas las pasiones.

La pregunta que muchos se hacen y deviene en este caso la más lógica, es la siguiente: ¿Queda Padura a la altura de las expectativas generadas por un libro como este? ¿Es buena 
la novela o no lo es? ¿Se trata, en realidad, de una novela...? Qué duda cabe: El hombre que amaba a los perros genera polémica.

Lo primero que me parece insoslayable destacar en un género como la novela histórica es la importancia capital de una investigación seria, profunda y sistemática de la materia elegida que anteceda y soporte a la ficción. Lo cual no significa que el escritor tenga que atarse forzosamente a la versión oficial o generalmente admitida de los hechos sobre los cuales escribe, porque todo escritor de novelas históricas dispone de un margen de interpretación personal del tema que ha investigado, y esta licencia resulta validada por la multiplicidad de versiones siempre existentes en torno a un suceso histórico. La Historia a pulso es cuestión de historiadores. La ficción tiene libertad de acción. No hay que ponerse, pues, a sacar cuentas de hasta dónde lo que narra Padura fue verdad porque, en esencia, todo es cierto.

El hombre que amaba a los perros impresiona desde sus primeras páginas por la exhaustiva investigación realizada. E impresiona todavía más porque no se trata de una investigación sobre la vida de Nerón, Carlomagno, la historia de Roma o cualquier acontecimiento del que nos separan una dimensión temporal considerablemente dilatada y una inmensa bibliografía repleta de firmas insignes, sino de hechos que estaban ocurriendo apenas unas décadas atrás, que marcaron irreversiblemente nuestra existencia y de los cuales apenas si conoce el mundo todavía más que la punta del iceberg. Creo necesario remarcar también que Cuba no me parece el contexto más fácil ni colaborador para que un particular lleve a cabo una pesquisa sobre los crímenes del stalinismo, y muy puntualmente el asesinato de Trotsky . La riqueza de información, la reconstrucción de hechos y escenarios, y la abundante papelería reunida por Padura en el transcurso de años — palpable en el producto final - merecen el mayor respeto, porque denotan al periodista incansable, el analista sagaz de información y al hombre comprometido con su época.

Discrepo de las aseveraciones hechas por algunos críticos referentes a la complejidad de la estructura narrativa empleada por Padura en su más reciente creación. Si bien es cierto que por encima de la voz narrativa del veterinario Iván —el joven desencantado que conoce a Mercader en una playa habanera y a quien este cuenta su historia-, se percibe otra voz, 
enigmática, indefinida y hasta fantasmagórica que, en ocasiones, se dirige al lector de un modo intempestivo y directo, la superposición de narradores per se no basta para calificar de compleja una estructura narrativa. Aunque esa hubiera sido la intención del autor, en realidad El hombre que amaba a los perros tiene una estructura lineal cuya mayor complejidad consiste en el uso del flashback y otras técnicas de retroceso, y en la dualidad de planos temporales en que transcurre la acción: el tiempo de Trotsky y el de Ramón Mercader, que son uno y el mismo, y el tiempo de Iván, muy posterior. Para Trotsky y Mercader, cuyas vidas siguen cursos paralelos, el tiempo es un presente que para Iván, es pasado. Pero al elegir un narrador que escucha $-\mathrm{y}$ cuenta - sobre sucesos de otra época mientras anda involucrado en los de su propia vida, inevitablemente se crea la ilusión de una estructura compleja, cuando lo que se está es en presencia de una estructura cronológica que se mueve sobre un triple solapamiento de destinos, pues como Trotsky, Mercader y tantos otros revolucionarios rusos que perdieron su fe, también Iván ha perdido la suya y su vida carece de norte y sentido: desde el principio está tan extraviado como ellos lo estuvieron. Insisto en que no se trata exactamente de un paralelismo estructural, sino más bien conceptual, y hasta pudiera calificársele de filosófico, en la medida en que sirve de soporte a la tesis suprema de la novela: demolición de un universo. En cuanto a ese narrador cuya sombra se proyecta por encima de Iván, más que un recurso que merezca celebración tal vez resulte, en el orden estilístico, un proceder innecesario, una debilidad que por momentos atenta contra la organicidad de la materia literaria.

Y he aquí algo a lo que quiero prestar especial atención: resultaría una exigencia demasiado fuerte pretender que todas las escenas a lo largo de más de 500 páginas muestren una construcción impecable. Es uno de los muchos riesgos que enfrenta un trabajo tan extenso y ambicioso. Pero, en general, Padura modela sus bloques narrativos y descriptivos con minuciosidad artesanal. Un oficio sólido y un ojo entrenado en la dinámica cinematográfica, sumados al hábito periodístico de una rápida calibración panorámica de caracteres, lugares y situaciones — destrezas que Padura posee en alto grado - le permiten atender con eficacia sostenida a los múltiples niveles que componen la arquitectura de su imaginario. Nada falta en cada puesta, en cada montaje, aunque algunos detalles sobren al 
extremo de resultar molestos, como aquel cenicero que Mercader sustrae del bar cercano al apartamento vacío que le ha entregado su mentor para que viva el tiempo que ha de pasar en París antes de partir para México a consumar su misión macabra. Porque si bien es cierto que los espías no son estereotipos sino individuos con múltiples flaquezas, me niego a creer que Mercader violara una regla tan elemental dentro del mundo del espionaje, como es la prohibición de poseer objetos que puedan suministrar a un enemigo potencial la más mínima información sobre su dueño. Es verdad que, tal como Padura ha concebido a su personaje, dentro de Mercader convive con el militante duro un auténtico ingenuo, a quien su mentor manipula a su antojo y de quien es capaz de obtener compromiso con silbos de sirena proletaria y, a veces, solo con insinuarle que su novia lo considera "un tipo blando" - por poner un ejemplo entre muchos a lo largo de la novela_-; pero robarse un cenicero con el logo de un bar de una ciudad donde se está haciendo estancia clandestina en vísperas de una importantísima misión, y que haga eso un hombre que ha pasado con éxito pruebas tan tremendas - impuestas por uno de los mejores servicios de espionaje del mundocomo son el tormento psicológico del borramiento de la personalidad real y la implantación de una falsa-, resulta un acto de candidez inconcebible, de infantilismo casi, que atenta contra la credibilidad del personaje. Hay aquí un quiebre de la lógica narrativa. Encontré a lo largo del libro varias acciones ejecutadas por personajes europeos que son ajenas al contexto sociocultural al que pertenecen, y ostentan, en cambio, un cierto aroma a conductas cubanazas. Me sucede lo mismo que a Trotsky, quien después de observar varias incongruencias en el comportamiento de Mercader termina cuestionándole en la cara su pretendida nacionalidad belga. La pared suena a hueco.

Una caracterización que me parece fallida por excesiva es la de Caridad, la madre de Mercader. No porque no resulte una entidad que persuade - el mundo siempre ha estado lleno de brujas y diablas como ella-, sino porque, por momentos, alguna que otra faceta suya se hipertrofia con una arrogancia que hace sospechar una malévola independencia del personaje con respecto a su creador, como cuando al principio de la historia fusila al perro de Mercader sin motivo alguno. Mucha gente mata perros, pero de ahí a balear al perro de un hijo ante sus ojos sin una razón que justifique semejante pax de merde... ¿qué aporta eso

Poligramas 37, primer semestre 2013, ISSN 0120-4130. 
al perfil psicológico de Caridad, engalanado con toda una constelación de atributos repulsivos que tan despreciable la tornan? ¿Una muestra de poder...? ¿Una marca de demencia? ¿Un galón de morbosidad? ¿Era necesario tanto énfasis en la oscuridad de esta mujer? ¿Había que sobrepasarse tanto en las pruebas para descalificarla como ser humano? Lo que la vida admite puede resultar un exceso en el arte, una demasía inconveniente, porque como ya dijo alguien —refiriéndose a las características del adjetivo-, lo que no da vida, mata, y aquí la frase se crece en su polisemia. Caridad se me antoja un concierto donde con incómoda frecuencia a un músico se le escapan notas fuera de registro.

Pese a algún que otro episodio fatal como el del cenicero, Ramón Mercader es un personaje de excelentísima factura, el cual, colocado en la platina del microscopio, convence por la coherencia de su sustancia, lo mismo que Trotsky, aunque en el caso del viejo comunista faltan, en mi opinión, ciertas pinceladas que hubieran matizado tal vez un nivel absoluto de convicción ideológica devenido fanatismo inquebrantable, y que, tal como está planteado en el libro, ocupa demasiado espacio en detrimento de un despliegue más enriquecedor de otros rasgos de la personalidad del exiliado. Sin embargo, lo que Padura hizo bien en su Trotsky está tan bien hecho que cumple el milagro de una plena animación.

Kotov, el ruso que tiene a su cargo a Mercader y lo entrena para el asesinato de quien fuera la mano derecha de Lenin, es otra creación muy sólida, aunque las razones y motivaciones que lo impulsaron a vivir como lo hizo resulten un tanto incomprensibles para el lector cubano, pero no es un defecto imputable a Padura, sino al hecho de que seres como Kotov pertenecen a un contexto y a unas circunstancias históricas que por fortuna, aunque tuvimos tan cerca, nunca llegamos a emular. El miedo no explica todo. Pienso que solo los alemanes de Hitler podrían comprender cabalmente tal fenómeno humano. Y quizá me equivoco: es posible que los nazis hayan sido menos sofisticados y retorcidos, mucho más directos en sus procedimientos para aterrorizar y destruir.

El resto de los personajes están trabajados con una técnica muy prudente; como en el cine, la cámara se les acerca y sigue en grados diferentes y en atención a lo estrictamente necesario para el flujo de la historia, sin permitir jamás que los secundarios usurpen el centro de la atención a las estrellas del show. Salvo en un caso: SilvyaAggelof, uno de los

Poligramas 37, primer semestre 2013, ISSN 0120-4130. 
personajes mejor concebidos por Padura a través de toda su obra, tanto que estuvo abocado a dejar de ser un secundario, no por su lugar en la trama de esta novela, sino por la minuciosa calidad de su trazado.

Aunque el libro tiene momentos de gran intensidad dramática, observo en el tono general una tesitura serena en verdad notable. Padura tiene bien agarrada su historia, y esa seguridad que se percibe durante todo el hecho artístico la asumo como consecuencia de un proceso de maduración dilatado, pero definitivamente establecido. Como en ninguna de sus novelas anteriores, el oficio de Padura se muestra en El hombre que amaba a los perros con una concreción ya poco susceptible de cuestionamientos. Creo que por eso la dramaturgia de esta novela se muestra eficiente de principio a fin. Solo, tal vez, aqueja cierta reiteración a los encuentros de Mercader con Iván en la playa, y aunque el autor trate de conferirles cada vez un aura diferente, es difícil escapar a la sensación de que se está leyendo la misma escena una y otra vez, apenas retocada. También incomoda la relación establecida entre Mercader y su mentor tras la muerte de Stalin, esa especie de borrón y cuenta nueva sazonada con vodka y coles rellenas que permite al asesino de Trotsky, después de veinte años de expiación (¡y de cárcel mexicana!), sentarse a la mesa amigablemente con el hombre que lo "monstrificó", y quien siempre lo manipuló a sabiendas de que lo estaba convirtiendo en cordero pascual. ¿Basta cualquier cantidad de razones históricas para paralizar de un modo tan total la capacidad de reacción de un ser humano? Es posible, pero aún así, como solución literaria carece de verosimilitud esta amistad tardía que recuerda de un modo inquietante el síndrome de Estocolmo. Tal vez como medida de degradación humana se justifique más.

Como miembro de la especie, pero sobre todo como lectora cubana, lo que más me interesa en la historia contada por Padura no es Ramón Mercader ni su culpa impurgable, ni la vida perseguida y la horrenda muerte de Trotsky, sino el naufragio apocalíptico de Iván. Porque aunque no niego la condición de víctimas históricas de los dos primeros (inseparable, por demás, de su gemela condición de verdugos), Trotsky y Mercader terminaron envenenados cada uno por los frutos de su elección personal, mientras que Iván fue empujado hacia el tormento y el matadero de todos los modos y por todos los caminos posibles, contra su

Poligramas 37, primer semestre 2013, ISSN 0120-4130. 
voluntad y sin que pudiera resistirse. Es su conflicto el que más profundamente me estremece, pues si bien las tragedias de Trotsky y Mercader consistieron en una mala elección del camino, la de Iván, por el contrario, se define por una absoluta carencia de opciones. Mientras el ruso y el catalán pertenecieron genuinamente a una estirpe de lobos y como tales vivieron, Iván encarna la tragedia natural de las ovejas. No por gusto, ni por pura solidaridad hacia el personaje, Padura lo dota solo a él de una esencia crística, manifiesta en el hecho de que, entre todos los personajes de la novela, sea el cubano el único capaz de sentir el más espiritual y desinteresado de los sentimientos: la compasión. La comprensión de esta clave puede y debe buscarla el lector en el plano simbólico y metatextual de El hombre que amaba a los perros, y en mi opinión habría sido preferible que la hallara por sí mismo, sin la ayuda de un Padura que en las páginas finales de la novela se permite un exceso didáctico —en mi opinión absolutamente innecesario y con el aura de un panfleto sutil—, cuando expone en un discurso desmenuzado cómo su personaje representa al pueblo cubano. Es obvio que el calvario de Iván se resume, en el plano del Micromundo, en una afirmación muy criolla: se "desgració" el día en que la máscara de Ramón Mercader apareció en aquella playa donde el pobrecito veterinario había ido, con la mayor inocencia de este mundo, a leerse su librito; pero también la lectura atenta de la novela deja perfectamente esclarecido que aunque parezca un fatum personal, en realidad el destino de Iván forma parte de un entramado contextual que rebasa el plano del individuo: en los entretelones del Macromundo su martirio toma la forma de una aberración histórica que es casi una hierofanía, y se subsume en una única, pero demoledora interrogante cuya respuesta entrañaría el más grave y rotundo de los emplazamientos: ¿Por qué paseaba a sus perros el asesino de Trotsky en una playa cubana? ¿Por qué debía pagar Iván el puro, el habanero Iván, el veterinario Iván, el sin pecados, la libra de carne de Shilock? Iván es tan bueno, que en su postrera conversación con su amigo Daniel aún niega que Mercader fuera un asesino, porque "él no andaba por ahí matando gentes... Fue un soldado que cumplió órdenes. Hizo lo que le mandaron por obediencia y convicción".

Yo no estoy escribiendo este artículo sobre El hombre que amaba a los perros para erigirme en juez de la Historia, sino para ejercer, como crítico, el derecho al ejercicio del criterio. No

Poligramas 37, primer semestre 2013, ISSN 0120-4130. 
voy a dar mi voto sobre la cuota de culpa, castigo y perdón que merecen Trotsky, Ramón Mercader y tantos de su especie. Pero como lector tomo el partido de Iván porque, aunque en su inocencia ontológica no pudo o no quiso aceptar la condición atroz de Mercader, este también lo mató a él, y por partida doble: primero, cuando cansado de arrastrar durante tanto tiempo su negro serón de culpas, ante las urgencias purificadoras de la Muerte lo descargó sobre Iván como quien lanza una indeseable bolsa de excrementos encima de un hombre bueno; segundo, cuando se introdujo en la cabeza de su víctima y le obligó a dejar de ser Iván para percibir el mundo con los ojos de Ramón Mercader, sin importarle cuán ajeno fuera el elegido a sus avatares militantes y a su pútrida costra interior, sin preocuparle si se trataba de un hombre con el caudal de fuerza necesaria para soportar un fardo semejante. El reclamo que invariablemente hacía a Iván en cada encuentro para que lo ayudara a incorporarse de la arena no es un gesto colocado por gusto en la novela, sino una cápsula perfundida del más alto simbolismo. Mercader enterró al cubano en vida bajo un túmulo de mierda ajena. He escuchado algunos comentarios inconformes sobre el final de Iván, sepultado en su cama junto a su perro por el desplome del techo de su vivienda. ¿Demasiado evidente la traslación simbólica? Pudiera ser. A mí no me disgusta, lo considero un final no exento de grandeza, y en tanto que pone punto final al combate de una vida, épico: el mejor final para una oveja compasiva. Cuando no se puede con el escudo, igual de digno resulta sobre el escudo. ¿No escribió Martí: “Me vengaré llorando?”. Es muy difícil que una obra tan extensa como esta novela no tenga lunares. Existe una lista de los lunares de La guerra y la paz, por solo citar un ejemplo. El lenguaje de Padura, directo y sin filigranas —adelgazado, como decía Virgilio Piñera cuando intentaba establecer diferencias entre su propio estilo y el barroquismo linguoestilístico de Lezamay ostentando en muchas páginas un alto vuelo literario, pero en la mayoría un sabor netamente periodístico, didáctico y testimonial, se resiente con frecuencia por la repetición de vocablos y consonancias en un mismo párrafo, errores de puntuación, lugares comunes y otras fallas elementales, pero no viscerales. Por otra parte, es un español efable y sin pretensiones esteticistas que sirve muy bien a la intención del autor. Nunca he creído que a Padura le haya interesado alguna vez ser un estilista del idioma. 
He visto en Internet algunas manifestaciones acerca de la densidad y "pesadez" de la novela. Para quienes están habituados al registro policíaco de Padura, una obra como esta, plagada de erudición histórica, puede resultar asfixiante y defraudar a los adictos de la acción por la acción. Pero para los que se acercan a su lectura guiados por el afán de conocimiento y con un mínimo de interés por comprender las paradojas de la Historia, nunca será una decepción. Y a esta última clase de lector tampoco le molestará que Padura se haya permitido manejar el suspense como lo hubiera hecho en una de sus novelas policíacas, porque el procedimiento, muy efectista en ocasiones, no basta para opacar los otros valores del texto; ni tampoco molestará a este lector hipotético que el libro sea tan voluminoso, pues cien cuartillas menos lo habrían convertido en una novela más sobre el terrorismo de Estado, pero las que tiene hacen de él un análisis muy atendible sobre lo perdido y lo salvable en la condición humana.

Afirmar que El hombre que amaba a los perros contiene tres novelas — como he leído en algunas reseñas breves ubicadas en Internet- me parece una boutade imperdonable. Padura armó su novela exactamente como tenía que hacerlo para decir lo que quiso decir. Si acaso sobrara algún elemento, sería, me parece, el huracán, aunque se salve por su categoría de fuerza de la Naturaleza arrasando las vidas de los hombres y las naciones.

Otros aspectos del texto que nos ocupa merecen atención, mas no pretendo (ni podría) agotar el tema, y para terminar me detendré en el que resulta, posiblemente, el más polémico de esta obra que tiene, por su propia naturaleza, un valor literario intrínseco y dos valores añadidos: el histórico y el político. ¿Cuál de los tres resulta de más peso a la hora de una valoración final? ¿Estamos en presencia de una gran obra literaria, de la mejor novela que se haya escrito en Cuba en las últimas décadas, como afirman los entusiastas; o nos enfrentamos a una descomunal muestra de excelencia periodística donde los valores añadidos rebasan al valor literario al punto de volverse valores intrínsecos y desplazar a este a la categoría de valor añadido? ¿Será Padura el único escritor importante surgido en las Letras cubanas durante el último medio siglo y la primera década del tercer milenio? No considero que en mi momentáneo papel de crítico esté obligada a ofrecer una respuesta a estas interrogantes. Creo más necesario mover la opinión en torno a un libro que pudiera 
catalogarse como el más valiente escrito en Cuba en mucho tiempo, aunque indudablemente tiene su peso (y no es poco) el hecho de que el amparo de un importante sello editorial extranjero reduzca en algún por ciento la incomodidad del riesgo implícito.

Guardo a Padura un pequeño y antiguo rencor por haber atacado muy torpemente décadas atrás una novela que yo, amante de la excelencia estilística, reverencio, y algunas personas conocen esta anécdota, pero quiero dejar constancia del respeto que me inspira una obra tan diáfana como El hombre que amaba a los perros; y de mi desacuerdo con quienes se han pronunciado en favor de su prescindibilidad, porque si bien este libro puede resultar interesante para cualquier habitante de la Tierra por lo que cuenta, resulta absolutamente necesario para nosotros los cubanos, no porque hable una vez más -aunque indudablemente mucho mejor de lo que tantos escritores vienen haciéndolo en estos tiempos de mala literatura- de balseros, éxodos y otras tragedias nacionales tan dolorosas como sabidas, sino porque nos ha revelado un acontecimiento de nuestra historia nacional que hasta hace muy poco ignorábamos, y del que, sin sospecharlo, fuimos cómplices. A partir de las revelaciones hechas por Padura en su novela, muchos de nosotros sentiremos adherirse a nuestra piel algunas partículas del malestar viscoso que devoraba el espíritu de Iván. Pero no siempre el violador es quien arranca la inocencia.

\section{Tomado de Hija del Aire}

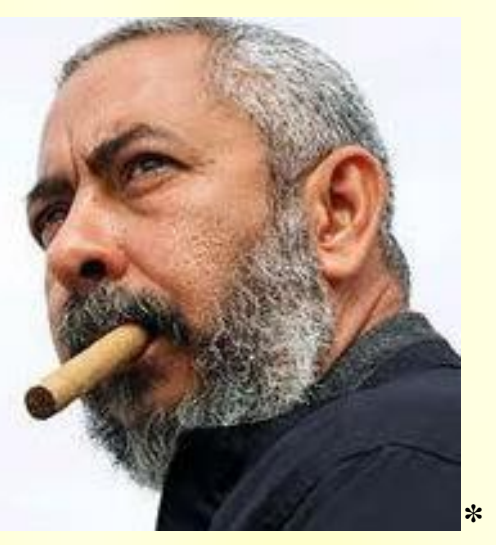

Leonardo Padura Fuentes (La Habana, 1955) es un

novelista y periodista cubano, conocido especialmente por sus novelas policíacas del detective Mario Conde: la tetralogía Cuatro estaciones: Pasado perfecto (1991), Vientos de cuaresma (1994), Máscaras (1997) y Paisaje de otoño (1998); Adiós Hemingway (2001) y La neblina del ayer (2002/2003) 
También:

Fiebre de caballos, novela, 1983/1984

Con la espada y con la pluma, ensayo sobre el Inca Garcilaso de la Vega, 1984

Colón, Carpentier, la mano, el arpa y la sombra, ensayo, 1987

Según pasan los años, cuento, 1989

Lo real maravilloso, creación y realidad, ensayo, 1989

El alma en el terreno, entrevistas.

El viaje más largo, 1994, reportajes.

Alejo Carpentier y la narrativa de lo real maravilloso, ensayo, 1995

La puerta de Alcalá y otras cacerías, cuento, 1997

Los rostros de la salsa, entrevistas, 1997

La cola de la serpiente, 2001

La novela de mi vida, 2005, novela histórico-detestivesca sobre el poeta cubano José María Heredia

La cenicienta de la novela, sobre el género policial.

El submarino amarillo, antología del cuento cubano entre 1966 y 1991

Poligramas 37, primer semestre 2013, ISSN 0120-4130. 